DOI: $10.17580 /$ cisisr.2020.02.10

\title{
QUANTITATIVE ASSESSMENT OF MICROSTRUCTURAL INHOMOGENEITY BY THICKNESS OF HOT-ROLLED PLATES MADE OF COLD-RESISTANT LOW-ALLOY STEEL FOR ARCTIC APPLICATIONS
}

\author{
A. A. Kazakov ${ }^{1}$, D. V. Kiselev², O. V. Sych³ , E. I. Khlusova ${ }^{3}$ \\ ${ }^{1}$ Peter the Great St. Petersburg Polytechnic University (St. Petersburg, Russia) \\ 2 “Thixomet” JSC (St. Petersburg, Russia) \\ ${ }^{3}$ National Research Center "Kurchatov Institute" - Central Research Institute of Structural Materials "Prometey" \\ (St. Petersburg, Russia)
}

\section{E-mail:kazakov@thixomet.ru}

\section{AUTHOR'S INFO \\ A. A. Kazakov, Dr. Eng., Prof., Head of "Metallurgical Examination" Lab., D. V. Kiselev, Technical Director, "Metallurgical Examination" Lab., O. V. Sych, Cand. Eng., Head of the Sector, E. I. Khlusova, Dr. Eng., Prof., Deputy Head of Scientific and Production Center No. 3 (NPK-3), Head of the Laboratory}

\section{Key words:}

cold-resistant plate steel, inhomogeneity by thickness, microstructural anisotropy, automated assessment on panoramic images.

\begin{abstract}
A B S T RAC T
A technique to assess microstructural anisotropy assessing by the thickness of the plate steel based on the texture analysis of the image has been developed. This technique provides for the anisotropy assessment at two dimensional levels: in the short-distance and long-distance neighborhoods, which characterize the elongation along the rolling direction of fine and coarse structural constituents, respectively.

The practical approval results of this technique in the study of the microstructural heterogeneity of ferritic-bainitic steels over the thickness of 25-70 $\mathrm{mm}$ hot-rolled plates have been presented. It has been shown that the proposed anisotropy criteria in combination with the volume fraction of coarse packet-block regions of lath bainite as well as regions of bainite without an internal developed subgrain structure adequately estimate the microstructural heterogeneity over the thickness of plate steel and can be used for a detailed interpretation of the two-stage thermomechanical processing technology with accelerated cooling including taking into account the metallurgical inheritance of the slab.
\end{abstract}

\section{Introduction and problem statement}

Cold-resistant steels for the manufacture of complex marine equipment operate in the Artic climate; therefore, they must guarantee the prevention of brittle fracture at temperatures down to -40 to $-60^{\circ} \mathrm{C}$. Until recently, the main criterion for evaluating the cold resistance of these steels was the impact energy, estimated at low test temperatures on specimens with a cross section of $10 \times 10 \mathrm{~mm}$ cut at the surface and from the middle of the plate. To make a judgment about the cold resistance of the plate throughout the entire thickness and thus assess the characteristics of its performance as a whole, static and dynamic tests are carried out on full-thickness specimens [1,2].

The critical temperatures of brittleness and fracture toughness determined during these tests are «structurally sensitive» and depend on the development of structural heterogeneity throughout the thickness of the plate steel; therefore, its quantitative assessment can become an objective basis for interpreting these properties, as well as evaluating the performance of thermomechanical processing and development ways to improve it. Such an assessment is especially important for cold-resistant shipbuilding ferritic-bainitic steel with a yield strength not less 355-460 MPa for the Arctic application, which is supplied in thicknesses up to $100 \mathrm{~mm}$, and in accordance with the new «Rules ...» of the Russian Maritime Register [3] can be supplied with a thickness of up to $150 \mathrm{~mm}$.
Despite the rather large experience in the manufacture of plate from low-alloy steels at Russian and foreign industrial enterprises, the tasks of a comprehensive quantitative assessment of the microstructure based upon the thickness of hot-rolled plate steel has not yet been solved, and the search for the relationship between the technological parameters of production and the parameters of the microstructure, on the one hand, and the performance characteristics, on the other hand, remain relevant $[4,5]$.

In this regard, the purpose of this work is the development and practical approval of a quantitative methodology for a comprehensive assessment of the microstructural heterogeneity throughout the thickness of $25-70 \mathrm{~mm}$ hot-rolled plates made of low-alloy cold-resistant steels with guaranteed performance.

\section{Development of a technique for assessing the anisotropy of the microstructure}

The technique for assessing the anisotropy of the microstructure is based on the texture analysis of images $[6,7]$, more precisely, on the construction of gray-level co-occurrence matrices, the elements of which represent the conditional probability $P_{d, \alpha}(i, j)$ of the appearance of a pixel with a gray level $i$ at a distance $d$ in the direction $\alpha$ from pixel with a gray level $j$. Such matrices are built in eight directions from each pixel. 
The homogeneity coefficient is calculated for each matrix:

$$
H_{d, \propto}=\sum_{i} \sum_{j} \frac{P_{d, \propto}(i, j)}{1+|i-j|} .
$$

The anisotropy coefficient $K_{a}$ is calculated as the coefficient of variation of the $H_{d, \alpha}$ values calculated for different directions:

$$
K_{a}=\frac{\sigma_{H}}{\bar{H}}
$$

Earlier [6,7], when studying the microstructure of pipeline steel plates, the value of $d$ was chosen equal to 100 pixels, and the study of the microstructure was carried out at a magnification of $\times 200$. The anisotropy coefficient, calculated at these values of $d$ and the magnification, that best correspond to the visual expert assessment of the previously investigated structures of pipeline steels, in particular, it reliably separated the structures of specimens cut in the longitudinal and transverse directions of rolling, and also adequately described the mechanical properties of pipeline steel plates [7]. At such a distance $d$, the anisotropy of coarse structural constituents is estimated, since it is calculated within a radius of $25 \mu \mathrm{m}$ from each pixel of the studied image. Let's call it "the anisotropy in the long-distance neighborhood" and denote it by $K_{a 100}$.

To assess the anisotropy of all fine constituents of the microstructure visible with the light optical microscope at the selected magnification, the anisotropy was calcu- lated at the smallest value of the parameter $d$ equal to one pixel. Let us call it "the anisotropy in the short-distance neighborhood" and denote it by $K_{a 1}$.

Fig. 1 shows the values of the anisotropy coefficients $K_{a 1}$ calculated for structures specially made with a graphical editor to test this technique.

These synthesized structures were prepared with three different anisotropies and two different sizes of structural constituents, which made it possible to simulate anisotropy studies at different magnifications or one magnification, but for structural constituents of different sizes.

As follows from these results in Fig. 1, such a technique gives comparable values of the anisotropy coefficients in the short-distance neighborhood $\left(K_{a 1}\right)$ at different sizes of structural constituents or the same sizes, but in images obtained at different magnifications.

The index of the anisotropic inhomogeneity according to Saltykov [8] or the anisotropy index according to ASTM E1268 [9] was chosen as an arbitration value for assessing the reliability of the anisotropy coefficient $K_{a 1}$ found in this way. The anisotropy index $A I$ is determined by the directional secant method using the formula:

$$
A I=\frac{N_{\perp}}{N_{\|}},
$$

where $N_{\perp}$ and $N_{\|}$are the number of intersections of the boundaries of structural constituents with secants, perpendicular and parallel to the rolling direction, respectively.
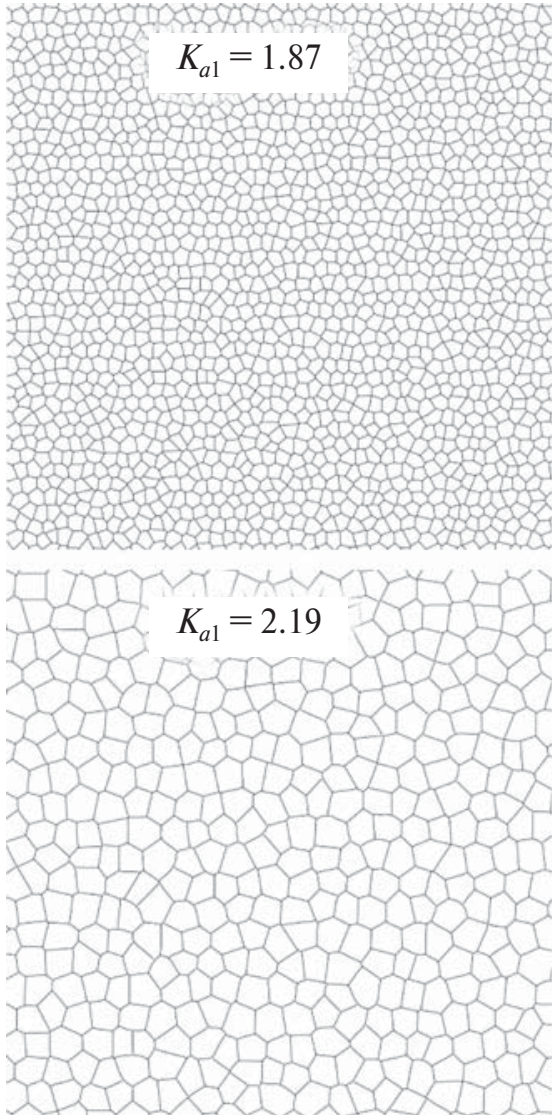
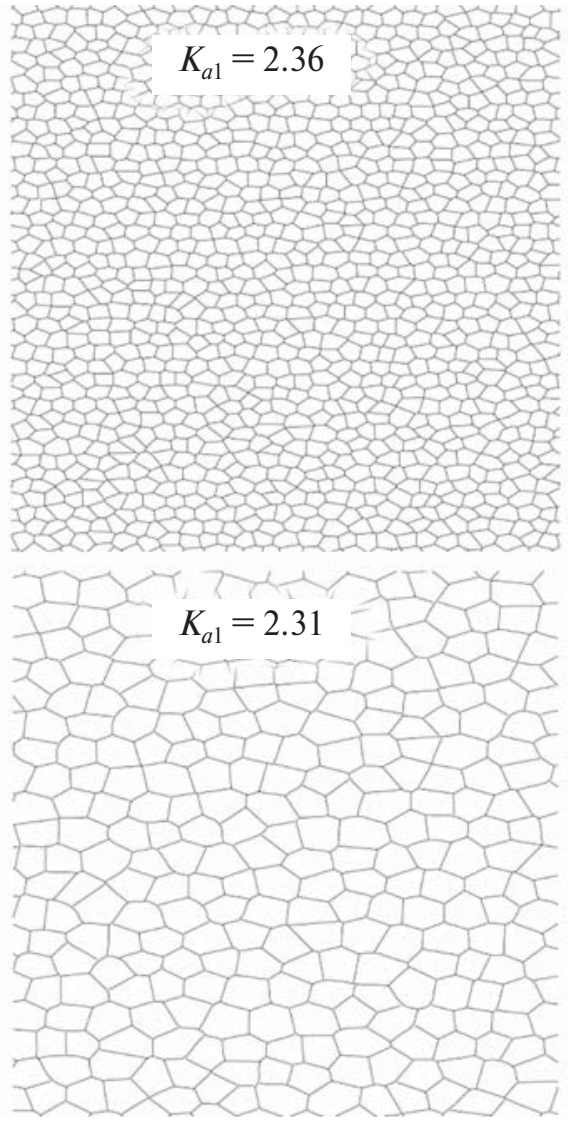
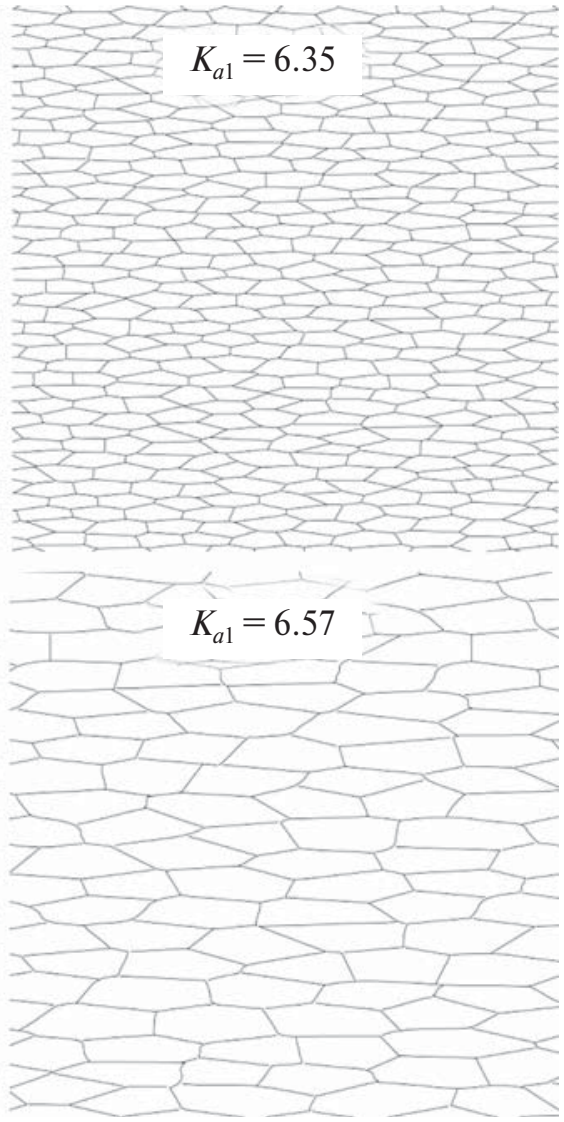

Fig. 1. Coefficient of anisotropy in the short-distance neighborhood $K_{a 1}$ using synthesized microstructures 

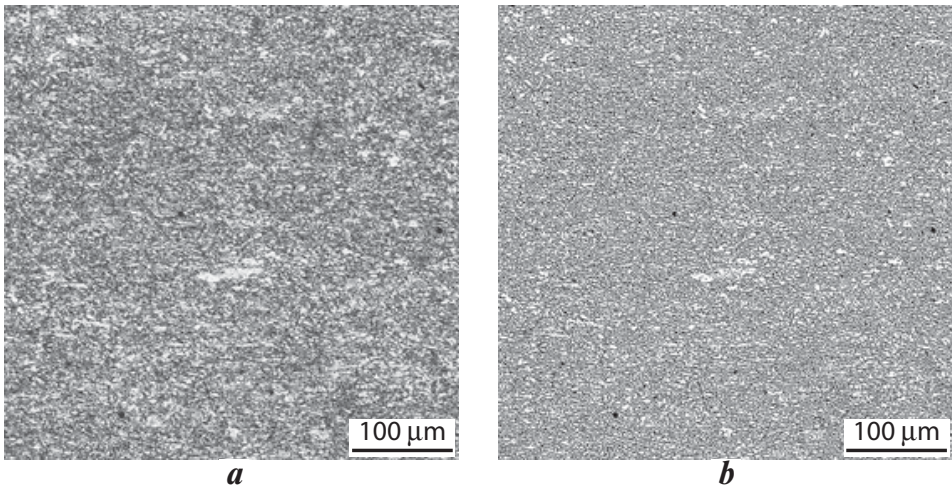

Fig. 2. Adaptive binarization of images of real microstructure: $a$ - a grayscale original image (etching with $4 \%$ nital); $b-$ a binarized image

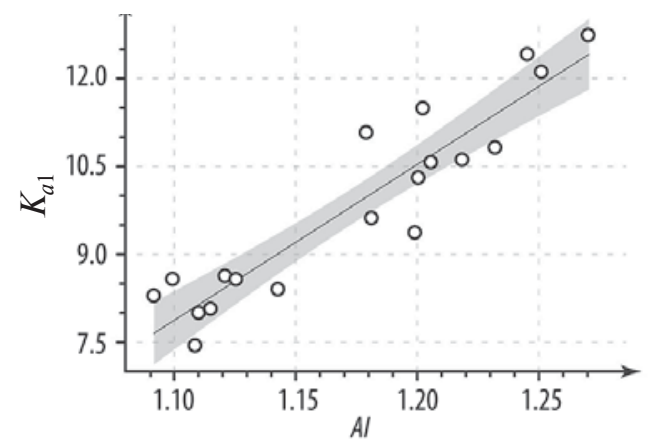

Fig. 3. The anisotropy coefficient in the short-distance neighborhood $K_{a 1}$ versus the anisotropy index $A I$ according to ASTM E1268
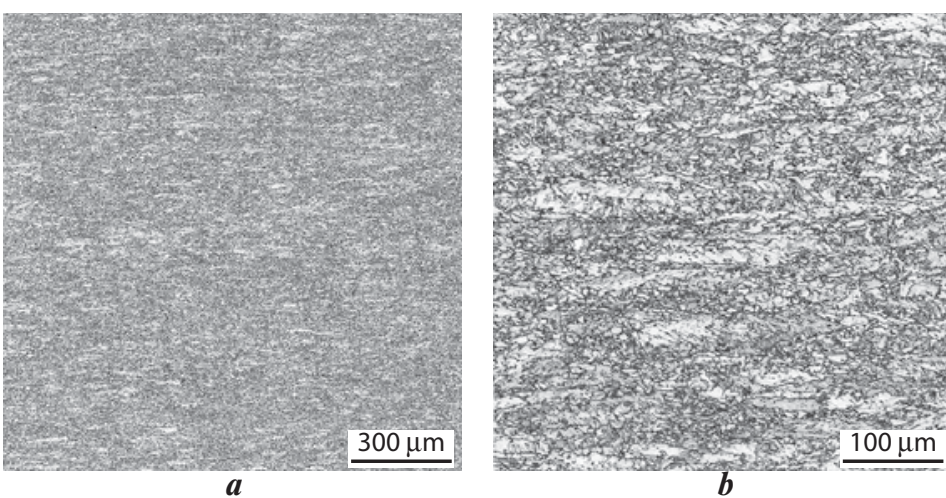

Fig. 4. Panoramic image of a microstructure with an area of $6 \mathrm{~mm}^{2}(a)$ and a fragment of this panorama with an area of $0.25 \mathrm{~mm}^{2}(b), \times 200$ (etching with $4 \%$ nital)

In order to ensure the operation of the directional secant algorithm and define $A I$, it is necessary to select the boundaries of the structural constituents on real grayscale images. For this, the images obtained at a magnification of $\times 200$ were processed using the adaptive binarization algorithm, which consists in the automatic selection of the binarization threshold for each pixel of the image according to the gray-level histogram for its local neighborhood shown in Fig. 2.

The size of the neighborhood was set in such a way that all visible boundaries were fully identified, but extra boundaries did not appear, which would become artifacts.
The binarization threshold was determined by the Otsu method [10]. Fig. 3 shows the dependence of the anisotropy coefficient $K_{a 1}$ versus the anisotropy index $A I$.

These values were obtained for images with a size of $500 \times 500 \mu \mathrm{m}$ cut from the full-scale $\left(6 \mathrm{~mm}^{2}\right)$ panoramic images of microstructures of plate steels with a thickness of 25,50 and $70 \mathrm{~mm}$. As follows from Fig. 3, the coefficient of anisotropy in the short-distance neighborhood $K_{a 1}$, found by the new technique, correlates well with the anisotropy index $A I$, calculated according to ASTM E1268.

If the above solution is found to determine the anisotropy in the short-distance neighborhood $K_{a 1}$, which "works" well for different sizes of structural constituents or for the same sizes, but in images obtained at different magnifications, then to determine the anisotropy in the long-distance neighborhood $K_{a 100}$, one should choose the magnification and representative measurement area for adequate assessment of the microstructure of the plates.

For a reasonable choice of these values, the following methodological work was carried out. The measurements were carried out using a successive series at different magnifications from $\times 50$ to $\times 500$ on several panoramas of different areas in each series. Panoramas were built on cross sections from plate $50 \mathrm{~mm}$ thick made of a low-alloy steel with a guaranteed yield strength of 420-460 MPa in the place near the plate surface where the metal structure was sufficiently homogeneous. On each of four large panoramas of the same area $\left(6 \mathrm{~mm}^{2}\right)$, but built at different magnifications $(\times 50, \times 100, \times 200$, and $\times 500$ ), small panoramas of different areas were cut out, on each of which $K_{a 100}$ was determined.

As an example, Fig. 4 shows a large panorama with an area of $6 \mathrm{~mm}^{2}(a)$ and its fragment with an area of $0.25 \mathrm{~mm}^{2}(b)$. Both panoramas were built at $\times 200$ magnification.

Based on the results of the obtained measurements, the average values of the anisotropy coefficient in the long-distance neighborhood $K_{a 100}$ and the error of its measurement, estimated by the confidence interval $C I$, were determined (Fig. 5). As follows from these results, at all investigated magnifications, the panorama area used to determine the anisotropy in the long-distance neighborhood has practically no effect on its average value, especially for magnifications $\times 200$ and $\times 500$ (Fig. $5, \boldsymbol{a}$ ).

The confidence interval of measurements $C I$ decreases with an increase in the area of the panorama on which these measurements were performed (Fig. 5, b): $C I<3 \%$ for all magnifications if the measurement area reaches $4 \mathrm{~mm}^{2}$ or more. The $\times 200$ magnification provides the smallest scatter and the smallest measurement error, and building a panorama with an area of $4 \mathrm{~mm}^{2}$ with this magnification is less laborious than with $\times 500$ magnifications. The $\times 200$ magnification was used earlier; therefore, such 


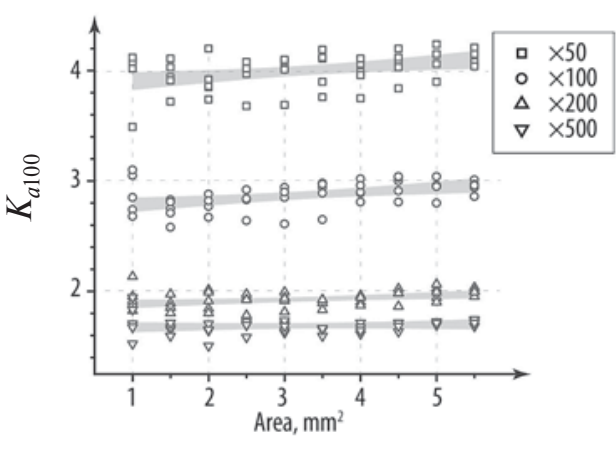

$\boldsymbol{a}$

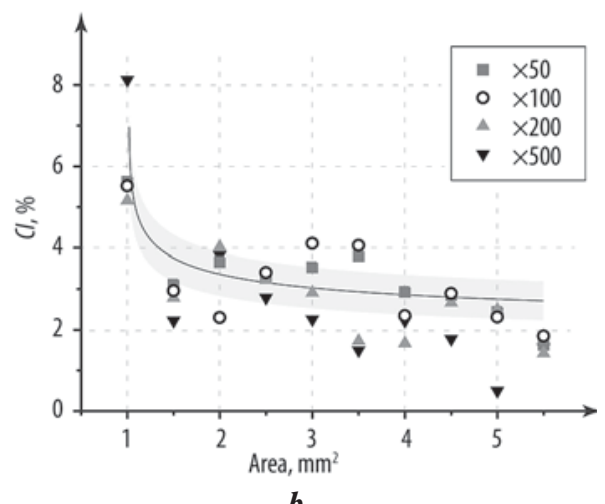

b

Fig. 5. The average value ( $a$ ) and measurement error ( $b$ ) of anisotropy in the long-distance neighborhood $\left(K_{a 100}\right)$ versus the panorama area

a choice will preserve the continuity of measurements of the microstructure of industrial hot-rolled plates carried out in different years [6].

Thus, on the basis of panoramic quantitative metallography using the Thixomet image analyzer, a technique for assessing the microstructural anisotropy of the plate steel at two dimensional levels: $K_{a 1}-$ in the short-distance and $K_{a 100}-$ in the long-distance neighborhoods, has been developed.

Approval of the technique for quantitative assessment of through thickness microstructural heterogeneity of plates made of low-alloy steel with a guaranteed yield strength of 420-460 MPa

Hot-rolled plates with a thickness of 25,50 and $70 \mathrm{~mm}$ were made from continuously cast slabs using the technology of two-stage thermomechanical processing which includes:

1) reheating of slabs, excluding significant growth of the primary austenite grains;

2) high-temperature (rough) stage of rolling according to the optimal method of deformation distribution over individual passes, providing austenite grain refinement due to recrystallization processes [11-13];

3) intermediate cooling-down of the semifinished rolled stock of optimal thickness at a defined ratio of integral deformations at the rough and finishing stages of rolling;

4) finishing stage of rolling at a temperature above the critical point $\mathrm{A}_{\mathrm{r} 3}$ according to a regulated temperature and deformation schedule, which ensures development of a grain structure in the austenite due to the processes of fragmentation and polygonization [14-15]; and,

5) accelerated cooling at a controlled rate to a given temperature within the bainite range, which ensures the inheritance of the structure of partially recrystallized and fragmented austenite during the $\gamma \rightarrow \alpha$ transformation [16].

With an increase in the thickness of the plate steel, it becomes more and more difficult to ensure the uniformity and completeness of the main structure-forming processes in the surface and central layers. For hot-rolled plates 70-100 mm thick, the temperature difference between the surface and the center can reach $100{ }^{\circ} \mathrm{C}$ [17], which, together with a low deformation rate and subsequent slow cooling, burdened by the metallurgical inheritance of the equiaxed zone of the slab, leads to the formation of an anisotropic ferrite-bainitic structure with large areas of lath morphology bainite formed within the former nonrecrystallized austenite grains.

Before presenting the results of a quantitative assessment of microstructural heterogeneity and discussing its behavior across the thickness of various plates in relation to the technology of their production, we will consider the metallographic features of the microstructure at specific points of the studied steel plates.

\section{Microstructures analyses of steel plates 25 and $50 \mathrm{~mm}$ thick}

The ferrite constituent in the structure of a low-alloy steel is represented by a quasi-polygonal ferrite shape, and the bainitic constituent is represented by granular bainite, bainite of lath morphology and bainite which does not have an internally developed subgrain structure [18]. For the convenience of further description, the last two types of bainite are named by a short conventional definition - "non-granular" bainite. The combination of these two types of bainite into one type is also justified by the fact that selective etching with an aqueous solution of sodium metabisulfite simultaneously reveals both of its morphological forms: bainite of lath morphology and bainite which does not have an internally developed subgrain structure.

A quasi-homogeneous ferritic-bainitic structure is generated over the thickness of the hot-rolled plate $25 \mathrm{~mm}$. In the near-surface layer (Fig. 6, a), the dispersed microstructure consists of granular bainite and quasi-polygonal ferrite with single regions of lath bainite and bainite that does not have an internally developed subgrain structure; the volume fraction of "non-granular" bainite is about $2 \%$. At a distance of up to $7 \mathrm{~mm}$ from the surface of the plate (see Fig. 6, c), still quasihomogeneous but already coarser structure is represented by granular and "non-granular" bainite, the volume fraction of the latter reaches $10 \%$. From the surface layers to the center of the plate, the fraction of "nongranular" bainite increases from $2-3$ to $13-18 \%$, and its 

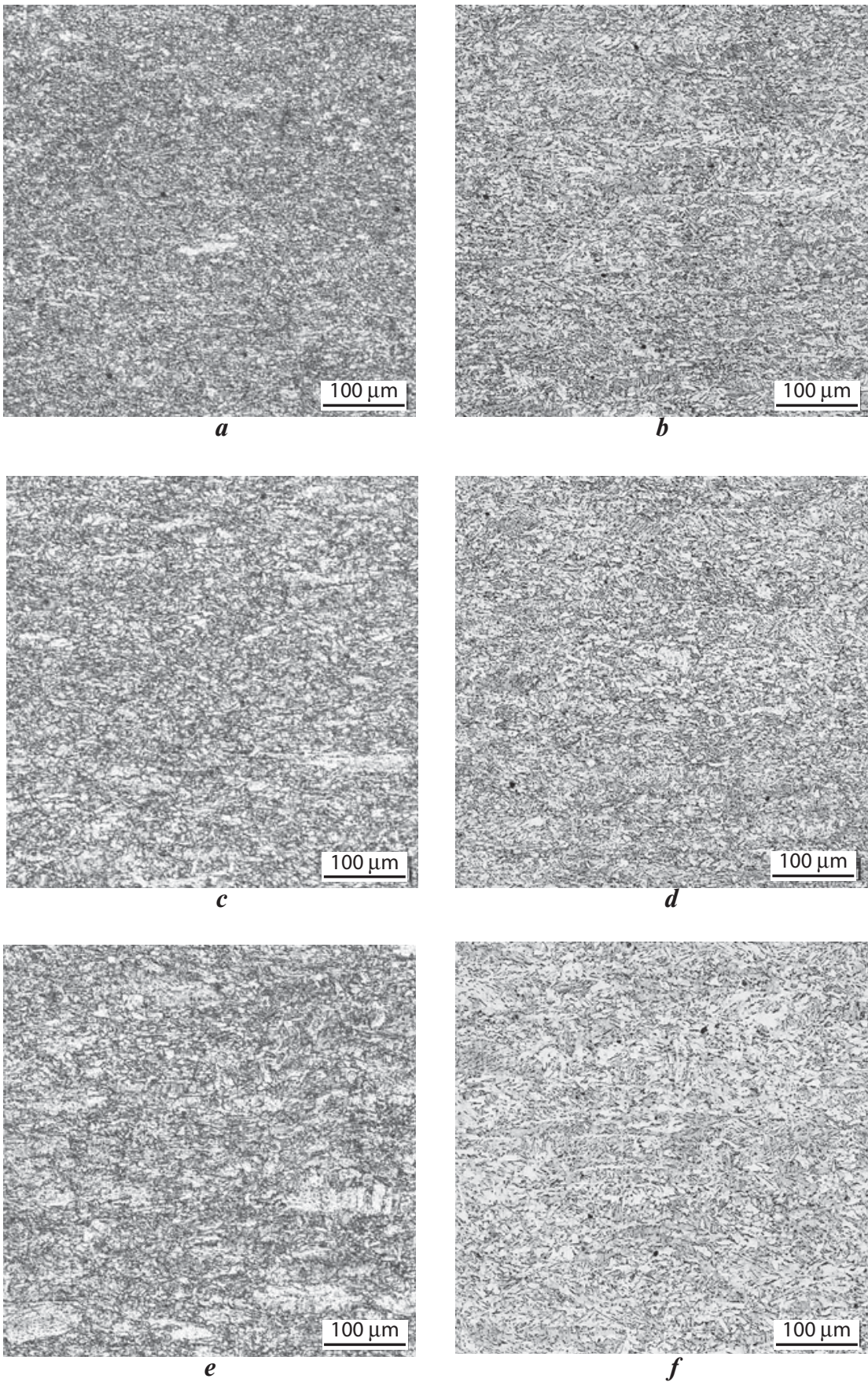

Fig. 6. Microstructure of plates $25 \mathrm{~mm}$ thick ( $a, c$ and $e$ ) and $50 \mathrm{~mm}$ thick (b, $d$ and $f$ :

$a$ and $b-$ near the surface; $c$ and $d-$ at quarter thickness; $e$ and $f-$ in the center of plates (etching with $4 \%$ nital)

length increases from $250 \mu \mathrm{m}$ (Figs. 6, $\boldsymbol{a}$ and $\boldsymbol{c}$ ) to $500 \mu \mathrm{m}$ $($ Fig. $6, \boldsymbol{e}$ ) at a distance of $7-8 \mathrm{~mm}$ from the surface and in the middle third of the plate, correspondingly.

Examples of through-thickness changes in the microstructure of the $50 \mathrm{~mm}$ steel plate are shown in Figs. 6, $\boldsymbol{b}$, $\boldsymbol{d}$ and $f$.

In the near-surface layer of the plate (see Fig. 6, b), a dispersed ferritic-bainitic microstructure is generated consisting of quasi-polygonal ferrite and bainite of granular and lath morphologies. Bainite, which does not have an internal subgrain structure, is practically not formed here.
In the region corresponding to a quarter of the plate thickness (see Fig. 6, d), the ferrite constituent, represented by quasi-polygonal ferrite, becomes coarser [19] and allotriomorphic ferrite appears along the boundaries of the former nonrecrystallized austenite grains.

A feature of the middle third structure of a plate $50-\mathrm{mm}$ thick is the generation of a coarse uneven-grained ferritic-bainitic structure, consisting of quasi-polygonal ferrite and bainite of granular and "non-granular" morphologies. Here, the fraction of bainite, which does not have an internally developed subgrain structure, increases. This suggests the occurrence of selftempering in the $\alpha$-phase (Fig. $\mathbf{6 ,} \boldsymbol{f}$ ). Allotriomorphic ferrite is still preserved here at the boundaries of the former austenite grains.

In plate steel $50 \mathrm{~mm}$ thick, the length of the "non-granular" bainite regions increases from $250 \mu \mathrm{m}$ near the surface to $500 \mu \mathrm{m}$ in the center of the plate. The volume fraction of "non-granular" bainitic regions also increases from $2-3 \%$ near the surface to $8-10 \%$ in the center of the plate.

\section{Microstructure of plate steel 70-mm thick}

As known [20], with an increase in the thickness of plate steel, its structural heterogeneity increases. At the near-surface layer of this steel plate, at a depth of up to $8 \mathrm{~mm}$, it exhibits all the structural constituents found in the previous plates at deeper locations: allotriomorphic ferrite along the boundaries of former austenite grains and bainite, which does not have an internally developed subgrain structure (Fig. 7, a).

At a quarter of the plate thickness, at a depth of $8 \mathrm{~mm}$ to $20 \mathrm{~mm}$ from the surface, the microstructure contains all the same constituents, but they become coarser (Fig. 7, b) due to a decrease in the plastic deformation intensity in combination with a higher temperature and lower cooling rate in comparison with the previous layer [21]. Along the boundaries of subgrains of the bainitic $\alpha$-phase, carbide particles are precipitated, which indicates the occurrence of auto-tempering processes. The volume fraction of the "non-granular" type bainite varies within a narrow range of $2-5 \%$ from the surface itself up to $20 \mathrm{~mm}$ deep inside the plate. 

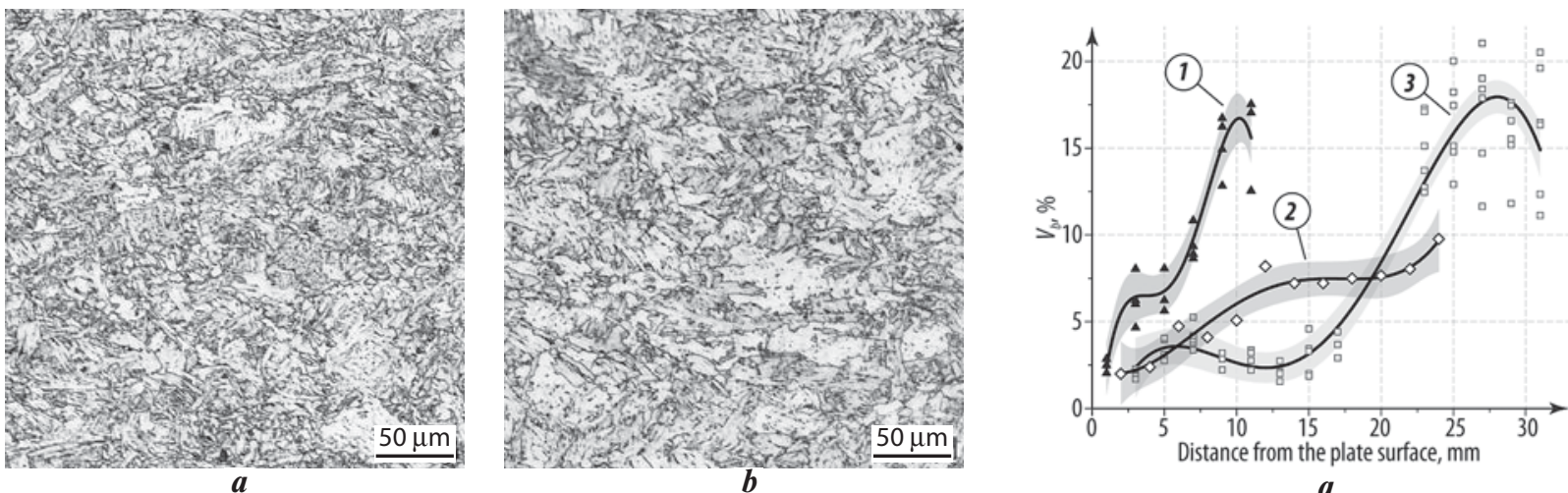

a
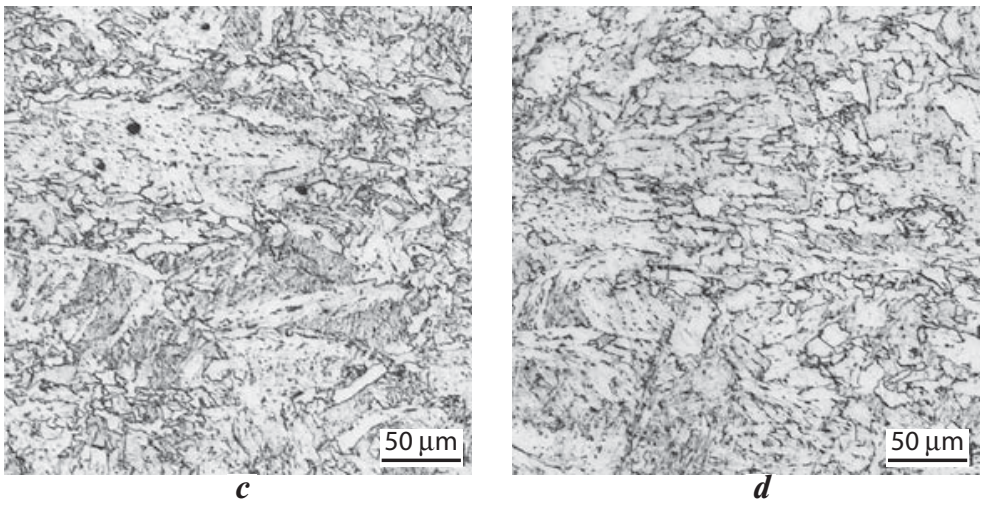

Fig. 7. Microstructures near the surface (a), at quarter thickness (b) and in the center $(c$ and $d)$ of $70 \mathrm{~mm}$ plate steel (etching with $4 \%$ nital)

In the central part of the plate at a distance of $20-35 \mathrm{~mm}$ from its surface, low deformation combined with high temperatures, low cooling rate, burdened by the metallurgical inheritance of the equiaxed zone of the continuously cast slab, enhance the heterogeneity of the ferritic-bainitic structure, and tempering processes intensify. In such a structure, transformed from practically non-recrystallized austenite, the volume fraction of "non-granular" type bainite increases to $11-21 \%$, and its distribution is of random nature (Figs. 7, $\boldsymbol{c}$ and $\boldsymbol{d}$ ).

\section{Quantification and interpretation of microstructural} heterogeneity of plate steels $25-, 50$ - and $70-\mathrm{mm}$ thick

As was shown earlier on the example of low-alloy pipeline steels [6, 7], it is the large regions of bainite of lath-type morphology with a size of more than $100 \mu \mathrm{m}$ that reduce all mechanical properties: impact strength, tensile strength and ductility of the steel, as well as steel resistance to brittle fracture at low climatic temperatures, estimated according to the results of dynamic tests with a drop-weight tear test (DWTT). Therefore, we measured the volume fraction of "non-granular" bainite larger than $100 \mu \mathrm{m}$.

The anisotropy coefficients in the short-distance $\left(K_{a 1}\right)$ and long-distance $\left(K_{a 100}\right)$ neighborhoods were estimated on panoramic images of $4 \mathrm{~mm}^{2}$ area at a magnification of $\times 200$ after etching a cross section with $4 \%$ nital. After repolishing this cross section and its repeated etching with an aqueous solution of sodium metabisulfite

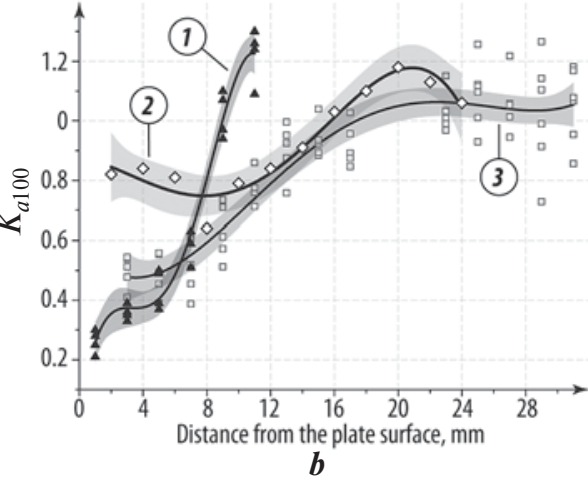

Fig. 8. Distribution of the volume fraction of "non-granular" bainite $V_{b}(a)$ and the anisotropy coefficient $K_{a 100}(b)$ for plate thickness of $25-\mathrm{mm}$ (1), 50-mm (2) and 70-mm (3)

( $10 \mathrm{~g}$ per $100 \mathrm{~g}$ of water), the volume fraction of "nongranular" bainite $\left(V_{b}\right)$ was determined in the same area. The technique of selective etching with sodium metabisulfite followed by analysis in polarized light has been described in detail in a patent [22].

For all steel plates, $V_{b}$ and $K_{a 100}$ increased from the surface to their center according to approximately the same nonlinear laws (Fig. 8), while the $K_{a 1}$ anisotropy decreased in the same direction, but according to an antisymmetric law (Fig. 9).

Using general considerations about the reasons for the steel structure evolution during the conversion of a continuously cast slab into hot-rolled plate, it is possible to explain the general trends in the change of the structural parameters that increased for $V_{b}$ and $K_{a 100}$ and decreased for $K_{a 1}$, as well as interpret some details of their nonlinear behavior over the thickness of the plates.

The distribution of microstructural characteristics $V_{b}, K_{a 100}, K_{a 1}$ over the thickness of the plate is directly related to the metallurgical inheritance of the continuously cast slab, on the one hand, and such features of hot rolling as the non-uniform distribution of temperature, deformation and cooling rates in its individual structural zones during the technological conversion of the slab into hot-rolled plate, on the other hand.

Indeed, the structure formation during two-stage thermomechanical treatment (TMT), which is most 


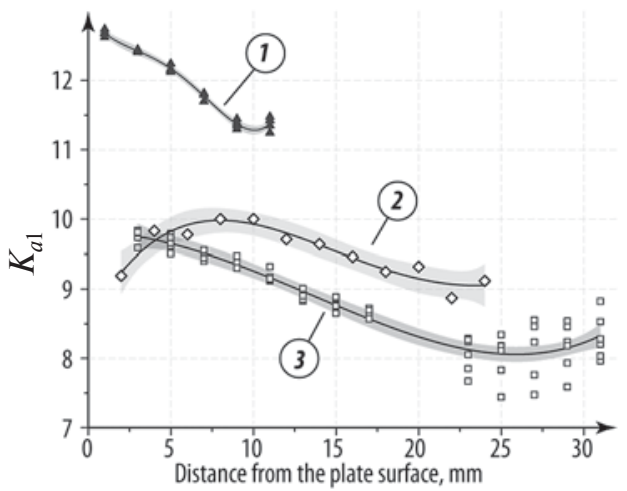

Fig. 9. Distribution of the anisotropy coefficient $K_{a 1}$ by plate thickness of $25-\mathrm{mm}(1), 50-\mathrm{mm}$ (2) and 70-mm (3)

widespread in the manufacture of shipbuilding steels, occurs under conditions of significant temperature-deformation inhomogeneity, which increases with an increase in the thickness of plate steel [17]. This heterogeneity from external impact during TMT is superimposed on the internal structural heterogeneity inherited from the continuously cast slab.

Therefore, when interpreting the nature of the $V_{b}$, $K_{a 100}$ and $K_{a 1}$ distributions over the thickness of the plate steel, one should take into account the cumulative effect of all the above factors on the formation of its microstructural heterogeneity.

Thus, the large columnar crystal zone of the slab, located near its surface, is directly affected by the most intense plastic deformation realized under the rolls; therefore, despite the colder surface of the plate, there is a significant refinement of the grain and subgrain structure of austenite and, as a consequence, the "non-granular" bainite fraction is minimal (see Fig. 8, $\boldsymbol{a}$ ), and the anisotropy for such a microstructure, estimated by the coefficient $K_{a 100}$, is low (see Fig. 8, b).

Moving towards the center of the plate, its temperature becomes higher, and the stress, weakened by the "dumping" of the surface layers of the first third of the plate thickness, becomes less. Under such temperaturedeformation conditions, the shear stresses arising from the movement of the metal in adjacent layers of the steel plate during hot deformation decreases. Therefore, the fraction of the structure with a developed subgrain structure decreases from the surface of the plate to its center, and the fraction of "non-granular" bainite and its anisotropy increases (see Fig. 8).

Note that the nonlinear increasing curves of the "nongranular" bainite fraction $V_{b}$ and the coefficient $K_{a 100}$ over the plate thickness are very similar (see Fig. 8). This indicates that the $K_{a 100}$ coefficient describes the anisotropy of coarse "non-granular" bainitic regions, which occur within the former non-recrystallized austenite grains, elongated along the rolling direction, under the temperature-deformation conditions mentioned above.

Let us focus on the central third of a plate formed from the central part of a continuously cast slab, which con- sists of a zone of large equiaxed crystals. In this zone, the branched skeletons of first and second order dendrites do not have a preferential growth direction, and the density of the dendritic structure of the central part of the slab is lower than in the zone with large columnar crystals, where the second-order axes are degenerate or completely absent. Therefore, during hot deformation, the "soft" rheology of the equiaxed crystals behavior with a low density of dendritic structure in the slab center is significantly different from the "hard" rheology of the large columnar crystals behavior with a high density of dendritic structure near the plate surface.

All the factors described above: a relatively high temperature in combination with a low stress, a low cooling rate and the inheritance of the slab central zone caused the formation of the most elongated non-recrystallized austenite grains along the rolling direction in the central third of the plate, and, as a consequence, the generation of a structure with the largest volume fraction and length of "non-granular" bainite and large ferrite grains (see Fig. 8, $a$ ).

The $K_{a 1}$ coefficient describes the anisotropy in the short-distance neighborhood for all fine structural constituents, distinguishable at a magnification of $\times 200$. Therefore, it is an "integral structural indicator" of the plastic deformation intensity and other thermo-deformation parameters at any specific point of the plate along its thickness.

Thus, under the influence of the largest stresses, there is the highest anisotropy $K_{a 1}$ in the near-surface layers of plates 25 and $70 \mathrm{~mm}$ thick, and the higher the thinner the plate (see Fig. 9). The plate $50 \mathrm{~mm}$ thick, due to the controlled cooling-down of the surface, has a rising branch of the $K_{a 1}$ - curve from the surface to a depth of $10 \mathrm{~mm}$. The cooling effect no longer works deeper, therefore, for this and other plates, the intensity of plastic deformation from the surface to the center decreases, and $K_{a 1}$ drops, reaching minimum values in the center of each plate. The thicker the plate, the lower the $K_{a 1}$ curve is (see Fig. 9). In the central part of the plate, inherited from the large equiaxed zone of the slab, the $K_{a 1}$ anisotropy is the lowest and remains practically constant, since, along with the above-mentioned metallurgical inheritance, this part of the plate is minimally "worked out". The thicker the plate, the lower $K_{a 1}$ and the wider the plateau of its minimum values: per 2.5, 5 and $10 \mathrm{~mm}$ on each side from the center of the plates 25-, 50- and 70-mm thick, respectively (see Fig. 9).

Note that the "integral structural indicator" $K_{a 1}$ (see Fig. 9) explains the trend in the $K_{a 100}$ and $V_{b}$ curves trend (see Fig. 8), which are similar for 25- and 70-mm plates and different for the $50-\mathrm{mm}$ thick plate. The abovementioned difference of producing a $50-\mathrm{mm}$ plate made it possible to obtain extremely flat distribution curves for $K_{a 100}$ and $V_{b}$ over the thickness of this plate, providing its unique characteristics of microstructural inhomogeneity.

Thus, the reasonable parameters for continuously cast slabs reheating, temperature-deformation rolling 


\begin{tabular}{|c|c|c|c|c|c|c|}
\hline Guaranteed yield strength & $\begin{array}{l}\text { Thickness of plate } \\
\text { metal, } \mathrm{mm}\end{array}$ & $\begin{array}{c}\text { Yield strength, } \\
\mathrm{MPa}\end{array}$ & $\begin{array}{l}\text { Tensile strength, } \\
\qquad \mathrm{MPa}\end{array}$ & Elongation, \% & $\begin{array}{l}\text { Reduction in the direc- } \\
\text { tion of thickness, } \%\end{array}$ & $\begin{array}{l}\text { Fracture } \\
\text { type, } \%\end{array}$ \\
\hline \multirow[t]{3}{*}{ Actual results } & 25 & 502 & 597 & 22.0 & 82 & 100 \\
\hline & 50 & 465 & 600 & 25.0 & 83 & 95 \\
\hline & 70 & 465 & 590 & 24.5 & 68 & 100 \\
\hline $420 \mathrm{MPa}$ & \multirow{2}{*}{$\begin{array}{c}\text { Requirements of GOST R } 52927 \\
\text { and RMRS [3] }\end{array}$} & Not less 420 & $530-680$ & Not less 18 & \multirow{2}{*}{ Not less 35} & \multirow{2}{*}{ Not less 90} \\
\hline $460 \mathrm{MPa}$ & & Not less 460 & $570-720$ & Not less 17 & & \\
\hline
\end{tabular}

\begin{tabular}{|c|c|c|c|c|c|c|}
\hline & \multirow{2}{*}{$\begin{array}{c}\text { Thickness } \\
\text { of plate metal, } \\
\mathrm{mm}\end{array}$} & \multicolumn{2}{|c|}{$\begin{array}{l}\text { Impact energy at test tem- } \\
\text { perature }-60^{\circ} \mathrm{C}, \mathrm{KV}-60, \mathrm{~J}\end{array}$} & \multirow{2}{*}{$\begin{array}{l}\text { Impact energy after strain aging and test } \\
\text { at temperature }-60^{\circ} \mathrm{C}, \mathrm{KVA}-60, \mathrm{~J} \\
\text { Surface }\end{array}$} & \multirow{2}{*}{$\begin{array}{l}\text { Ductile-brittle tran- } \\
\text { sition temperature } \\
{[1-2],{ }^{\circ} \mathrm{C}}\end{array}$} & \multirow{2}{*}{$\begin{array}{l}\text { Temperature of } \\
\text { zero plasticity } \\
\text { NDT, }{ }^{\circ} \mathrm{C}\end{array}$} \\
\hline & & Surface & Mid-thickness & & & \\
\hline \multirow{3}{*}{ Actual results } & 25 & $274-282$ & - & $160-195$ & -65 & -75 \\
\hline & 50 & $280-331$ & $250-275$ & $330-336$ & -35 & -80 \\
\hline & \begin{tabular}{|l|}
70 \\
\end{tabular} & $236-299$ & $260-265$ & $217-325$ & - & - \\
\hline \multicolumn{2}{|c|}{$\begin{array}{l}\text { Requirements for steel with index } \\
\text { "Arc40" RMRS [3] }\end{array}$} & \multicolumn{3}{|r|}{ Not less 80} & $\begin{array}{c}\text { Not higher } \\
-40 /-15 \\
(25 / 50 \mathrm{~mm})\end{array}$ & $\begin{array}{c}\text { Not higher } \\
-55 /-65 \\
(25 / 50 \mathrm{~mm})\end{array}$ \\
\hline
\end{tabular}

schedules and parameters of accelerated cooling, selected considering the peculiarities of the distribution of these parameters over the intermediate section of the billets with an increase in the thickness of the steel plates and ensuring the successive grain and sub-grain refining of the austenitic structure at each stage of the technological stream, provide a ferritic-bainitic structure with an anisotropy coefficient $K_{a 100}$ not exceeding 1.2, over the entire thickness of hot-rolled plates 25- to 70-mm thick. Such structural heterogeneity is acceptable and ensures a high level of all standard mechanical properties (Table 1), as well as cold resistance characteristics (Table 2).

\section{Conclusions}

The panoramic quantitative metallographic technique for microstructural anisotropy assessment by the thickness of the plate steel based on the textural analysis of the images has been developed. The technique specifies the assessment of anisotropy at two dimensional levels: in the short-distance $K_{a 1}$ and in the long-distance $K_{a 100}$ neighborhoods to describe fine and coarse structural constituents, respectively.

Coefficient $K_{a 100}$ describes the anisotropy of coarse packet-block regions of lath bainite and bainite regions that do not have a developed internal subgrain structure, conventionally called "non-granular" bainite, as well as coarse ferrite grains.

Coefficient $K_{a 1}$ describes the anisotropy of all fine structural constituents distinguishable at $\times 200$ magnification; therefore, it is an "integral structural indicator" of the plastic deformation intensity and other thermaldeformation parameters at the corresponding specific point of the plate along its thickness.

The proposed anisotropy coefficients in combination with the volume fraction of "non-granular" bainite larger than $100 \mu \mathrm{m}, V_{b}$, adequately assess the ferritic-bainitic structure inhomogeneity of low-alloy plate steels along the thickness and can be used for its detailed interpretation with account taken of features relating to both twostage thermomechanical processing with accelerated cooling and the metallurgical inheritance of the slab.

Parameters $V_{b}$ and $K_{a 100}$ increase according to the same nonlinear laws from the surface of plate steel to its center, and the anisotropy $K_{a 1}$ decreases in the same direction, but according to the inversely symmetric law:

the large columnar crystals zone of a continuously cast slab, located near its surface, is under the most intense plastic deformation. Therefore, despite the colder surface of the plate, there is a significant refinement of the austenite grain structure and, as a consequence, the "non-granular" bainite volume fraction, $V_{b}$, and anisotropy $K_{a 100}$ are minimal;

from the surface to the center of the steel plate, the temperature becomes higher, and the stress, weakened by the "dumping" of the surface layers, is less; therefore, the shear stresses arising from the movement of the metal in adjacent layers of the plate during its hot deformation decrease, and the "non-granular" bainite fraction, $V_{b}$, and anisotropy $K_{a 100}$ increase;

in the central zone of the steel plate, a relatively high temperature in combination with a low intensity of plastic deformation, affecting large equiaxed crystals inherited from the slab, caused the formation of the most elongated non-recrystallized austenite grains along the rolling direction, and, as a consequence, the formation of the largest volume fraction of predominantly "non-granular" bainite with the highest anisotropy;

under the influence of severe plastic deformations in the near-surface layers of the steel plate, the anisotropy of all the smallest constituents of the structure, $K_{a 1}$, is greatest and decreases as the intensity of plastic deformation decreases from the surface to the center of the plate, while the overall level of $K_{a 1}$ is higher, the thinner the plate. 


\section{REFERENCES}

1. Gusev M. A., Ilyin A. V., Larionov A.V. Certification of shipbuilding materials for ships operating in the Arctic. Shipbuilding. 2014. No. 5 (816). pp. 39-43.

2. Filin V. Yu. Quality control of steels for large-sized welded constructions for the Arctic shelf. Application of Russian and foreign requirements. Voprosy Materialovedenia. 2019. No. 2(98). pp. 136-153.

3. ND No. 2-020101-114. Rules for the classification and construction of sea-going ships. Part XIII. Materials. St. Petersburg: Russian Maritime Register of Shipping. 2019. p. 241.

4. Isasti N., Jorge-Badiola D., Taheri ML, Uranga P. Microstructural Features Controlling Mechanical Properties in $\mathrm{Nb}-\mathrm{Mo}$ Microalloyed Steels. Part II: Impact Toughness. Metallurgical and Materials Transactions A. 2014. Vol. 45. pp. 4972-4982.

5. Hu J., Du L. X., Zang M., Yin S. J., Wang Y. G., Qi X. Y., Gao X. H., Misra R. D. K. On the determining role of acicular ferrite in V-N microalloyed steel in increasing strength-toughness combination. Materials Characterization. 2016. Vol. 118. pp. 446-453

6. Kazakov A. A., Kiselev D. V. Industrial application of Thixomet Image Analyzer for quantitative description of steel and alloys microstructure. Metallography, Microstructure, and Analysis. 2016. Vol. 5. No. 4. pp. 294-301.

7. Kazakov A. A., Kiselev D. V., Pakhomova O. V. Quantitative description of microstructure for structure-property relationships of pipeline plate steel. CIS Iron and Steel Review. 2012, Vol. 7. pp. 4-12.

8. Saltykov S. A. Stereometric metallography. $3^{\text {rd }}$ edition, revised and enlarged, Moscow: Metallurgiya. 1970, $376 \mathrm{p}$.

9. ASTM E1268-19, Standard Practice for Assessing the Degree of Banding or Orientation of Microstructures, ASTM International, West Conshohocken, PA, 2019, www.astm.org.

10. Otsu N. A Threshold Selection Method from Gray-Level Histograms. IEEE Transactions on Systems, Man, and Cybernetics. 1979. Vol. 9. No. 1 (Jan.). pp. 62-66.

11. Gorelik S. S., Dobatkin S. V., Kaputkina L. M. Recrystallization of metals and alloys. Moscow: Izdatelskiy dom MISiS. 2005. $432 \mathrm{p}$.
12. Opiela M., Ozgowicz W. Effects of Nb, Ti and V on recrystallization kinetics of austenite in microalloyed steels. Journal of Achievements in Materials and Manufacturing Engineering. 2012. Vol. 55/2. pp. 759-771.

13. Sakai T., Belyakov A., Kaibyshev R., Miura H., Jonas J. J. Dynamic and post-dynamic recrystallization under hot, cold and severe plastic deformation conditions. Progress in Materials Science. 2014. Vol.60. pp. 130-207.

14. Rybin V. V. Large plastic deformation and destruction of metals. Moscow: Metallurgiya. 1986. 224 p.

15. Koneva N. A., Trishkina L. I., Kozlov E. V. Physics of substructural and grain-boundary strengthening. Fundamental problems of modern materials science. 2014. Vol. 11. No. 4. pp. 522-528.

16. Isasti N., Jorge-Badiola D., Taheri M. L., Uranga P. Phase Transformation Study in Nb-Mo Microalloyed Steels Using Dilatometry and EBSD Quantification. Metallurgical and materials transactions A. 2013. Vol. 44. pp. 3552-3563.

17. Goli-Oglu E. A., Bokachev Yu. A. Thermomechanical treatment of low-alloy structural steel plates up to $100 \mathrm{~mm}$ thick in NLMK DanSteel. Stal. 2014. No. 9. pp. 71-78.

18. Poletskov P. P., Denisov S. V., Nikitenko O. A., Chukin D. M., Gushchina M. S. Investigation of the decomposition of supercooled austenite in low-carbon pipe steel using the Gleeble 3500 complex. Izvestiya vysshikh uchebnykh zavedenii. Chernaya metallurgiya. 2019. Vol. 62. No. 3. pp. 235-240.

19. Hai-long Yi, Lin-xiu Du, Guo-dong Wang, Xiang-hua Liu. Bainite Transformation Under Continuous Cooling of $\mathrm{Nb}$ Microalloyed Low Carbon Steel. Journal of Iron and Steel Research, International. 2006. Vol. 13(3). pp. 36-39.

20. Goli-Ogly E. A., Kichkina A. A. Micro- and nanostructural nonuniformity through the thickness of $100 \mathrm{~mm}$ structural steel plate after TMT and HT. Metallurgist. 2017. Vol. 60. No. 11-12. pp. 1161-1168.

21. Nastich S. Y., Matrosov M. Y. High-strength pipe steel structure formation during thermomechanical treatment. Metallurgist. 2016. Vol. 59. No. 9-10. pp. 784-794.

22. Kazakov A. A., Kazakova E. I., Kiselev D. V., Kurochkina O. V. Investigation method of pipe steel's structure. Patent RUS 2449055 18.10.2010.

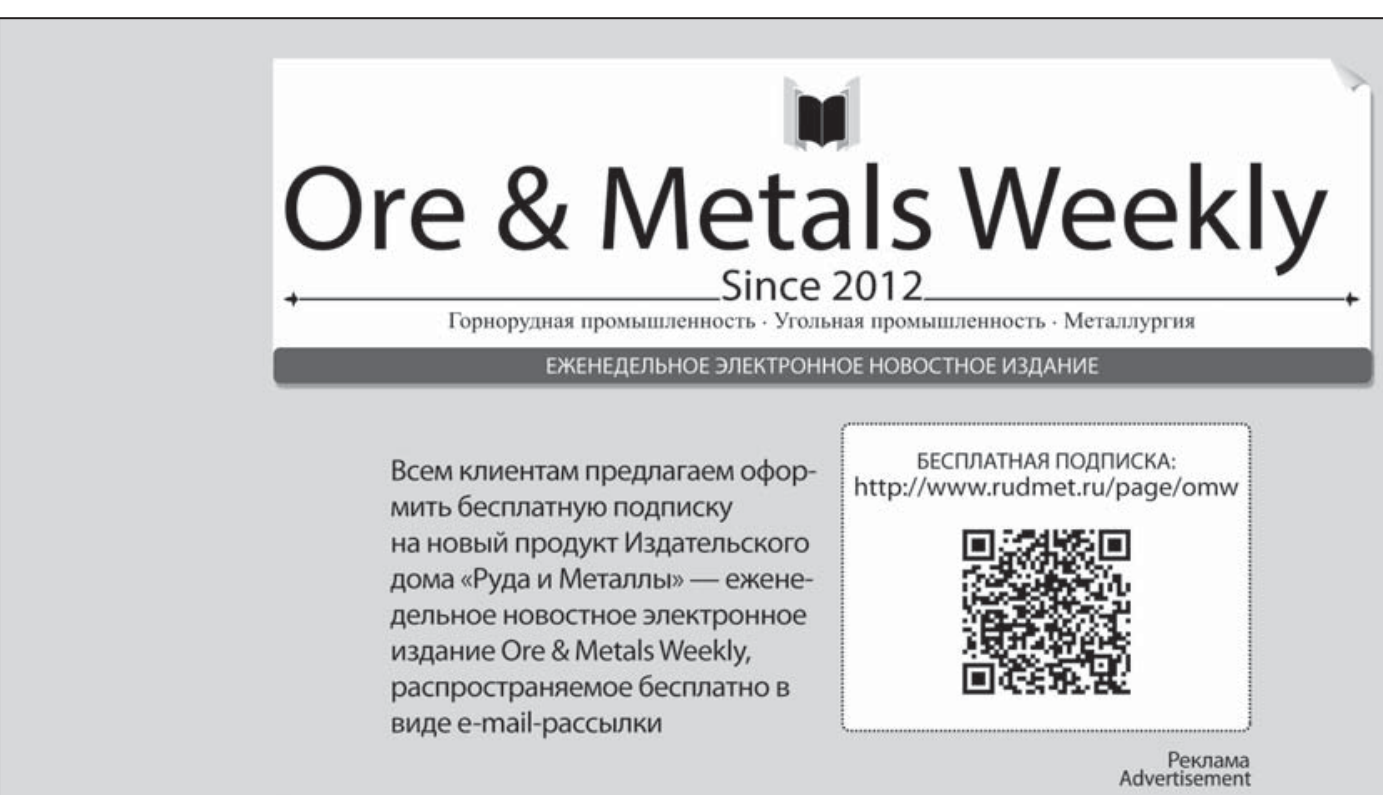

All customers are invited for free subscription to the new product of "Ore and Metals" Publishing House E-newspaper "Ore \& Metals Weekly" that is distributed free of charge as direct e-mailing. 